\title{
Vascular plants in the tourist area of Lushan National Nature Reserve, China: status, threats and conservation
}

\author{
Wang Hui, Tan Ceming, Xiong Wen, Wang Xuan, Aierkaixi Dahan \& Fu Qiang \\ Keywords: forest community, habitat fragmentation, Lushan Mountain, non-native species, vascular plants
}

\section{Abstract}

Lushan National Nature Reserve, one of the hotspots of montane plant diversity, is undergoing disturbance from human activities, especially plant introduction, road construction and tourism. Our survey carried out in 2015 and 2016 identified 563 vascular plant species, belonging to 337 genera and 114 families, distributed along the main tourism routes. 157 of the species are endemic to China and 3 to Lushan. 26 species are threatened with extinction and 15 are ancient relic species. 131 are introduced species which have become established in the survey area, and 17 of these are invasive species. Current knowledge indicates that the native plant fauna has been modified. The shrub and herb layers include a large number of introduced and domesticated plants. Conservation suggestions for local biodiversity are emphasized in this study.

\section{Profile}

Protected area

Lushan National Nature

\section{Reserve}

Mountain range

Lushan Mountain,

\section{China}

\section{Introduction}

The reduction of alpine habitat and loss of montane plant diversity have become severe problems worldwide (Pauli et al. 2012). This process is believed to be driven by habitat degradation and fragmentation, over-exploitation, biological invasion and climate change, among other factors (Tabarelli et al. 1999; Raxworthy et al. 2008; Sherman et al. 2008; Zhang et al. 2017). In montane regions with high disturbance caused by human activities, the risk of local extinction increases. However, empirical evidence for plant diversity in mountain systems is mostly found in historical records. Relatively little is known about the conservation status of native plants, or about the effects of human disturbance on plant diversity.

For this study, we conducted an investigation of Lushan Mountain, which has a long history of human use and has become a popular tourist resort. An inventory of vascular plant species was compiled. Endemic, endangered and introduced species were identified, as well as important threats to plant diversity.

\section{Study area}

Lushan Mountain (total area: approximately $302 \mathrm{~km}^{2}, 29^{\circ} 28^{\prime}-29^{\circ} 45^{\prime} \mathrm{N}, 115^{\circ} 50^{\prime}-116^{\circ} 10^{\prime} \mathrm{E}$ ) is located in Southern China, close to the Yangtze River. Lushan National Nature Reserve, covering Lushan Mountain in its entirety, was established in 2013, for the conservation of the subtropical forest ecosystem and historical sites. Lushan Mountain is a biodiversity hotspot for montane plants, harbouring a high number of endemic, rare and endangered species (Huang 1989; Flora Editorial Committee of Jiangxi 1993). Evergreen broad-leaf forests and deciduous broad-leaf forests co-occur and cover up to $76.6 \%$ of the land
(Yuan et al. 2011). A total of 2331 plant species (belonging to 204 families and 1019 genera) are distributed over Lushan Mountain (Flora Editorial Committee of Jiangxi 1993). The number of vascular plant species was recorded by Huang (1989) as 1912, belonging to 187 families and 833 genera.

Lushan Mountain has a long history of human uses. Large-scale exploitation, deforestation and plant introduction occurred from 1895 to 1934 (Tan 2015). Lushan Botanical Garden (Chinese Academy of Sciences) was established in 1934, followed by mass introductions of rare and valuable plant species (Huang \& Lei 2006). By 2008, the number of introduced plant species had reached 2285, of which at least 127 have escaped from cultivation and spread in the wild (Wan et al. 2008). Three roads were built between 1955 and 2006, causing habitat fragmentation all over the mountain (Wan et al. 2008). Tourist numbers to Lushan, as a destination famous for its natural landscape and historic culture, have reached 12 million per year since 2011 (LGA 2019).

\section{Method}

The survey was conducted along all the main tourist routes, which extend in different directions. The total length of the routes surveyed was $21.3 \mathrm{~km}$ (Figure 1). In different seasons during 2015-2016, we recorded all vascular plants along the routes. Plants that could not be identified in situ were collected and identified according to Flora of China.

For each species, we researched information about life form, extinction risk and endemism, and whether the species was an ancient relic species or a native species of Lushan. For non-native species, we searched for information about time of introduction, region of origin and invasiveness. We gathered our information 


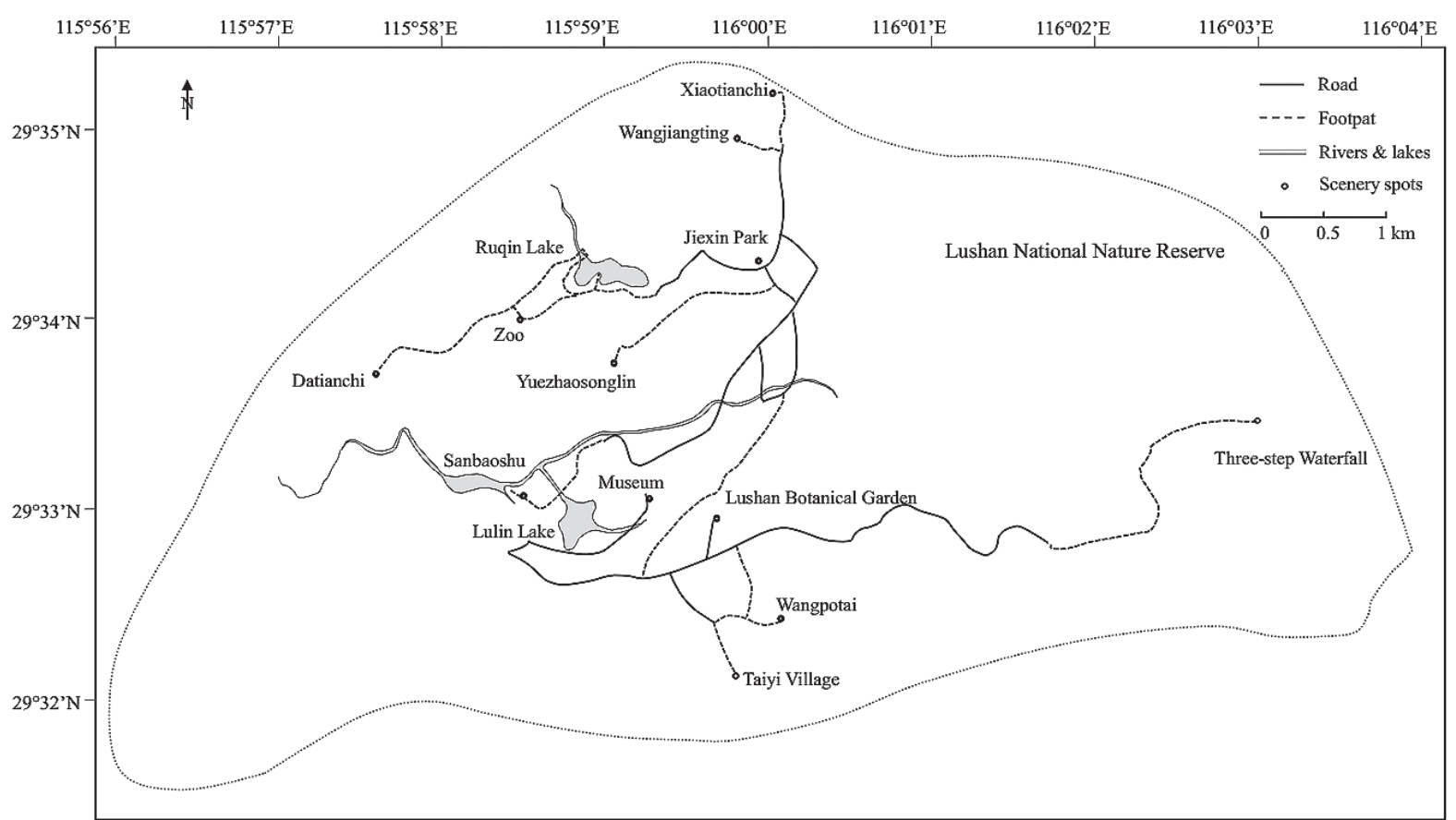

Figure 1 - The location of the surveyed routes.

from diverse sources. We checked region of origin in Lushan plants (Zhao \& Chen 1989), Species List of Lushan Plants (Lushan Botanical Garden 1982), Flora of China, Scientific Database of China Plant Species, and Catalogue of Life. We recorded species as endemic or ancient relic species according to Flora of China. For extinction risk, we checked the IUCN Red List of Threatened Species and the Chinese biodiversity red list (Chinese Ministry of Environmental Protection \& Chinese Academy of Sciences 2013). Life form was checked in Flora of Chi$n a$ and Vegetation of China (China Vegetation Editorial Board 1980). Information on plant introduction was checked in the published literature and unpublished grey sources. The invasiveness of non-native species was recorded according to Database of Invasive Alien Species in China. We also recorded the naturalized alien plants according to sources in the literature (references are listed in supplementary Table S1, online available).

\section{Results and Discussion}

Plant species richness and endemism

A total of 563 vascular species (including varieties and subspecies), belonging to 114 families and 337 genera, were recorded (Table S1). Rosaceae (55 species), Compositae (28 species) and Gramineae (26 species) are the most species-rich families. There are 341 species of trees and shrubs (112 species are evergreen and 229 are deciduous), 204 herb species and 18 vine species.

A total of 157 species (belonging to 65 families) are endemic to China. Three species, Dryopteris pseudobissetiana, Sedum baileyi and Galinsoga quadriradiata, are endemic to Lushan. 7 species are named after Lushan or the local town of Kuling: Lonicera modesta var. lushanensis, Wikstroemia pilosa var. kulingensis, Rubus kulinganus, Vicia kulingiana, Berchemia kulingensis, Ampelopsis heterophylla var. kulingensis, Philadelphus sericanthus var. kulingensis.

The constructive species belong to Fagaceae, Cornaceae, Juglandaceae and Aceraceae - for instance, $C y$ clobalanopsis myrsinifolia, Cornus controversa, Platycarya strobilacea and Acer davidii. The shrub layer is dominated by Rosaceae (32 species), Caprifoliaceae (12 species), Ericaceae (10 species), Lauraceae (8 species) and Camelliaceae ( 7 species). The herb layer is dominated by Compositae (28 species), Gramineae (20 species) and Urticaceae (11 species). The dominant and constructive species found on Lushan Mountain are common in a subtropical-temperate mountain climate. The tree layer is relatively stable, but the shrub and herb layers are dominated by introduced and domesticated plants (Wu \& Xie 2004). This appearance is typical of disturbed forests.

Threatened and ancient relic species

According to the IUCN Red List, 26 plant species are threatened species, of which 5 are endangered, 8 vulnerable and 16 native to Lushan. Non-native threatened species such as Calycanthus chinensis and Manglietia insignis were introduced for conservation and study (Chen 1994). There are also some species that were introduced for ornamental use, for example Chamaecyparis obtuse and Thuja standishii (Wan et al. 2008).

There are 15 ancient relic plant species, such as Liriodendron chinense, Ginkgo biloba and Metasequoia glyptostroboides. Of these ancient relic species, 5 are threatened with extinction and 13 are native to Lushan. 
Three ancient trees (a ginkgo and two trees of Cryptomeria fortunei), which are over 1500 years old, are protected from tourists by fences.

\section{Plant introduction and invasion}

A total of 131 plant species have been introduced into the surveyed area, amounting to $23.09 \%$ of the total plant species surveyed. The dominant families are Cupressaceae (17 species), Rosaceae (12 species) and Compositae (11 species). 58 species were introduced from other countries, and the majority originated from America (29 species), Japan (14 species) and Europe (11 species). 58 species were introduced from other regions of China and 15 species are cultivars.

We recorded 17 invasive species, of which the majority belong to Compositae (7 species) and Leguminosae (3 species). 16 are herb species. Robinia pseudoacacia is the only tree species. Most originate from America (14 species) and Europe (3 species). At least four invasive species were introduced by Lushan Botanical Garden - for instance, Solidago canadensis (introduced in 1936) (Huang \& Lei 2006). The introduction records of other invasive species are lacking.

Lushan Mountain has a long history of plant introduction. Ginkgo biloba was introduced thousands of years ago. Some ornamental plants and garden tree species, such as Chamaecyparis obtuse (introduced in 1919) and Abies firma (introduced in 1928), were introduced during when Lushan was developed for population migration and urbanization. Since 1934, Lushan Botanical Garden has conducted mass plant introductions, and some species have escaped from cultivation and spread into the wild. Invasive species appear constantly in the carparks, coach park and public green spaces, and elsewhere. Some invasive species have widely established feral populations along the surveyed routes, for example Coreopsis grandiflora and Alternanthera philoxeroides.

Threats to plant diversity and conservation approach

Plant introduction is an important factor that alters the plant fauna. Invasive species and the habitat fragmentation caused by the construction of roads are the most serious threats to the plant community in Lushan Mountain. In order to maintain the stability of the ecosystem and native biodiversity, conservation efforts should include:

(1) establishing conservation areas and habitat protection, which would decrease the influence of human disturbance, improve habitat quality, and guarantee the survival and regeneration of local plants;

(2) risk assessment before plant introduction. The complex environment of Lushan provides suitable habitats for numerous species, so there is a high risk that some noxious species could establish wild populations and spread (Wang et al. 2017). The invasion risk of herb species and species originating in similar climatic zones deserves more attention;
(3) control of invasive species and re-establishing native vegetation, for example by removing invasive plants and restricting their regeneration;

(4) monitoring of introduced species. A database of introduced plants should be built, and the distribution and dynamics of exotic plant populations should be monitored.

\section{Acknowledgements}

The authors are grateful to Peng Yansong and Yi Yongmei for assistance in plant identification. This research was supported by the National Natural Science Foundation of China (No. 31600189).

\section{References}

Catalogue of Life. Available at: http://www.catalogueoflife.org/

Chen, H. 1994. Profile of introduction of rare endangered plants by Lushan Botanical Garden. Plants 4: 13. [In Chinese]

China Vegetation Editorial Board 1980. Vegetation

of China. Science Press.

Chinese Ministry of Environmental Protection \& Chinese Academy of Sciences. 2013. Chinese biodiversity red list (volume of higher plants).

Database of Invasive Alien Species in China Available at: http://www.chinaias.cn/wjPart/index.aspx

Flora of China. Available at: http:// foc.eflora.cn/

Flora Editorial Committee of Jiangxi. 1993. Flora of Jiangxi. Volume 1. Nanchang: Jiangxi Science and Technology Press. [In Chinese]

Huang, B.L. \& R.H. Lei 2006. Investigation of foreign plants introduced in Lushan Botanical Garden between 1934 and 1958. Academic Annual Meeting of National Botanical Gardens. [In Chinese]

Huang, Y.X. 1989. Preliminary studies on the flora geography in the Lushan Mountain. Journal of Fujian Teachers University (Natural Science) 5(3): 96-102. [In Chinese]

IUCN Red List of Threatened Species. Available at: http:/ /www.iucnredlist.org/

LGA (Lushan Government Administration) 2019. Available at: http://lushan.jiujiang.gov.cn/home/ index.php.

Lushan Botanical Garden. 1982. Species List of Lushan Plants. Unpublished. [In Chinese]

Pauli, H., M. Gottfried, S. Dullinger, et al. 2012. Recent plant diversity changes on europe's mountain summits. Science 336(6079): 353.

Raxworthy, C.J., R.G. Pearson, N. Rabibisoa et al. 2008. Extinction vulnerability of tropical montane endemism from warming and upslope displacement: a preliminary appraisal for the highest massif in madagascar. Global Change Biology 14(8): 1703-1720.

Scientific Database of China Plant Species. Available at: http://db.kib.ac.cn/eflora/Default.aspx 
Sherman, R., R. Mullen, H. Li et al. 2008. Spatial patterns of plant diversity and communities in alpine ecosystems of the Hengduan Mountains, northwest Yunnan, China. Journal of Plant Ecology 1(2): 117-136.

Tabarelli, M., W. Mantovani \& C.A. Peres 1999. Effects of habitat fragmentation on plant guild structure in the montane Atlantic forest of southeastern Brazil. Biological Conservation 91(2-3): 119-127.

Tan, C.M. 2015. Common plant of tourist route in Lushan Mountain. Jiangxi Science and Technology Press. [In Chinese]

Wan, H.L., Z.W. Feng \& H.D. Pang 2008. On the exotic plants in Lushan, Jiangxi Province, China. Acta Ecologica Sinica 28(1): 0103-0110. [In Chinese]

Wang, Y.J, H. Müller-Schärer, M. Van Kleunen et al. 2017. Invasive alien plants benefit more from clonal integration in heterogeneous environments than natives. New Phytologist 216: 1072-1078.

Wu, C.J. \& G.W. Xie 2004. Diversity of wild ornamental plant resources in Lushan Mountain. Journal of Mountain Science 22(4): 508-513. [In Chinese]

Yuan, Y.R., X.F. Wang \& G.L. Gao 2011. Evaluation on the landscape of ancient and famous trees in lushan [J]. Journal of Anbui Agricultural Sciences 39(25): 15432-15433. [In Chinese]

Zhang, M.G, J.W.F. Slik \& K.P. Ma 2017. Priority areas for the conservation of perennial plants in China. Biological Conservation 210: 56-63.

Zhao, B.H. \& D.M. Chen. 1989. Lushan Plants. Hubei Education Press. [In Chinese]

\section{Authors}

Wang Hui

is a lecturer in Forestry at Huazhong Agricultural University. She has a $\mathrm{PhD}$ in Ecology from Wuhan University. Her research interests relate to biological conservation in forest ecosystems. E-mail: wanghui@ mail.hzau.edu.cn

\section{Tan Ceming ${ }^{2}$}

is a Senior Engineer in forestry. He is the founder of the Forest Herbarium of Jiujiang. His research focuses on the taxonomy of forest plants. E-mail: 1244546214@qq.com

\section{Xiong Wen ${ }^{3}$}

is a lecturer at Guangdong Ocean University. He has a $\mathrm{PhD}$ in botany. His research focuses on biological invasion and biodiversity conservation in vulnerable habitats. E-mail: chinaxiongwen@gmail.com

\section{Wang Xuan'}

is an undergraduate at Huazhong Agricultural University where she is majoring in landscape architecture. E-mail: 952812005@qq.com

\section{Aierkaixi Dahan'}

is an undergraduate at Huazhong Agricultural University where she is majoring in landscape architecture. E-mail: 1406338170@qq.com

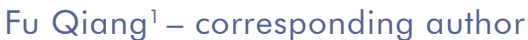

is a Senior Engineer in landscape architecture. He has a Master's degree in Landscape Plants and Horticulture. His research focuses on the taxonomy of plants and the cultivation of horticultural plants. Email: fuqiang@mail.hzau.edu.cn

${ }^{1}$ College of Horticulture \& Forestry Sciences / Hubei Engineering Technology Research Center for Forestry Information, Huazhong Agricultural University, Wuhan 430070, Hubei, China.

${ }^{2}$ Forest Herbarium of Jiujiang, Jiujiang 332000, Jiangxi, China.

${ }^{3}$ College of Fisheries, Guangdong Ocean University, Zhanjiang 524088, Guangdong, China 